\title{
CANCER
}

\section{Proximal adenomas in hereditary non-polyposis colorectal cancer are prone to rapid malignant transformation}

\author{
F E M Rijcken, H Hollema, J H Kleibeuker
}

See end of article for authors' affiliations

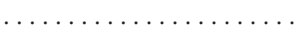

Correspondence to: Professor J H Kleibeuker, Department of

Gastroenterology, University Hospital Groningen, PO Box $30.001,9700 \mathrm{RB}$

Groningen, the Netherlands;

J.H.Kleibeuker@int.azg.nl

Accepted for publication 17 July 2001
Gut 2002;50:382-386

\begin{abstract}
Background: Hereditary non-polyposis colorectal cancer (HNPCC) is thought to arise from adenomas. HNPCC mostly occurs in the proximal colon. We investigated whether this proximal preponderance is due to a proximal preponderance of adenomas or (also) differences in transformation rates from adenomas to cancer between the distal and proximal colon.

Methods: A total of 100 HNPCC adenomas were evaluated and compared with 152 sporadic adenomas for location, size, and dysplasia. Twenty five adenomas from patients with a known mismatch repair (MMR) gene mutation were stained for expression of $M L H 1$ and MSH2.

Results: HNPCC adenomas were more often located proximally $(50 \% v 26 \% ; p=0.018)$ and were smaller in comparison with sporadic adenomas. They were similarly dysplastic. However, all proximal HNPCC adenomas $\geqslant 5 \mathrm{~mm}$ were highly dysplastic compared with $17 \%$ of the larger proximal sporadic polyps $(p<0.001)$. They were also more often highly dysplastic than larger distal HNPCC adenomas $(p<0.001)$. Small HNPCC adenomas were, except for their location, not different from sporadic adenomas. Fifteen of the 25 "known mutation" adenomas showed loss of expression of either MLH1 or MSH2. The 10 adenomas with expression were all small with low grade dysplasia.

Conclusion: HNPCC adenomas are located mainly in the proximal colon. The progression to high grade dysplasia is more common in proximal than distal HNPCC adenomas, indicating a faster transformation rate from early adenoma to cancer in the proximal colon. MMR gene malfunction probably does not initiate adenoma development but is present at a very early stage of tumorigenesis and heralds the development of high grade dysplasia.
\end{abstract}

$\mathrm{F}$ or the first time, researchers have obtained indisputable data supporting the use of contemporary colorectal cancer prevention procedures in hereditary non-polyposis colorectal cancer (HNPCC) syndrome. ${ }^{1}$ These data reveal a significant patient survival advantage and a reduction in the incidence of colorectal tumours following colonoscopic screening and polypectomies. This complies with the accepted adenoma-carcinoma sequence theory that states that adenomas are a precursor in the tumorigenesis of malignant HNPCC lesions. ${ }^{2-4}$

The malignant lesions, often occurring at a relatively young age, are well described in HNPCC. They are located predominantly in the proximal part of the colon, and there is a high incidence of synchronous and metachronous cases. Microscopically, the tumours are characterised by a Crohn's-like lymphoid reaction, a mucinous component, and poor differentiation. ${ }^{5-10}$ Studies on adenomas in HNPCC are less consistent. When calculating the average distribution of HNPCC adenomas in the literature, 45\% (range 27-70\%) were located in the proximal colon. ${ }^{19^{11-14}}$ Some reported an obvious propensity for right sided neoplastic lesions ${ }^{15}$ while others observed a distribution of adenomas in HNPCC patients similar to that in the general population..$^{13} 17$

The adenoma-carcinoma sequence in HNPCC seems to be accelerated. This is especially illustrated by the relatively frequent occurrence of cancers within the first few years after a "clean" colon had been confirmed by colonoscopy. ${ }^{14}{ }^{15}{ }^{18} 19$ In addition, several authors reported that HNPCC adenomas frequently have a villous component and high grade dysplasia, two assumed markers of increased risk of developing cancer. ${ }^{911}{ }^{1420}$ However, whether this is a uniform feature of all HNPCC adenomas at every location in the colon has yet to be determined. The ratio of proximal to distal cancers in HNPCC
(7:3) is higher than the reported ratio for adenomas (4:5). Thus it seems that not all HNPCC adenomas have an increased risk of malignant transformation and that there are regional differences in this respect.

In order to examine these issues, we compared adenomas resected from HNPCC patients with sporadic adenomas. More importantly, we investigated whether differences exist between proximal, distal, and rectal HNPCC adenomas.

\section{Methods \\ Patients}

According to the prevention guidelines of the International Collaborative Group on HNPCC (ICG-HNPCC), patients fulfilling the Amsterdam criteria and/or with a germline mismatch repair (MMR) gene mutation should undergo a colonoscopy every two years starting at the age of 25 years. ${ }^{21-23}$ At the University Hospital of Groningen, 136 subjects belonging to 47 families participated in a surveillance programme. We included all subjects with a positive colonoscopy in our study group: 46 ( 24 male and 22 female) patients with a median age of 50 (range 25-78) years at polypectomy. Sixty nine colonoscopies, a mean of 1.6 per patient (range 1-5), yielded 100 adenomatous polyps ( 55 from men and 45 from women) over a 12 year period from 1988 to 2000 . Four polyps found in a subtotal colectomy specimen were also included. Seven patients had previously been diagnosed with cancer and had part of their colon resected.

Abbreviations: HNPCC, hereditary non-polyposis colorectal cancer; MMR, mismatch repair; PBS, phosphate buffered saline; BSA, bovine serum albumin. 
The data were compared with findings from a control group consisting of sporadic adenomas consecutively removed during sigmoido- and colonoscopy at the Endoscopy Centre, University Hospital of Groningen in 1997. Lesions from patients with a strong positive family history of colorectal cancer or patients with ulcerative colitis, Crohn's disease, or familial adenomatous polyposis were excluded. According to the protocol, patients with an adenoma detected at sigmoidoscopy should subsequently undergo colonoscopy: except for two patients, the entire large bowel was inspected in each subject. $^{24}$ The group of sporadic adenomas consisted of 152 adenomas and had a similar male-female ratio as the HNPCC group (84 lesions in men and 68 in women). Mean age at polypectomy was 64 (range 24-90) years.

\section{Location}

The location of the adenomas was retrieved from endoscopy or pathology reports. The caecum and ascending and transverse colon are regarded as the proximal or right sided colon while the descending and sigmoid colon are referred to as the distal or left sided colon. The third location of the adenomas was the rectum.

\section{Histological examination}

Thin slides $(3 \mu \mathrm{m})$ were made of each formalin fixed paraffin embedded polyp and stained with haematoxylin-eosin. Two of the authors (FEMR and $\mathrm{HH}$ ) reviewed and scored three characteristics of the adenomas: (1) Size of the polyp-the microscopic measurement of the polyp's circumference: $<5 \mathrm{~mm}$ (small) and $\geqslant 5 \mathrm{~mm}$ (large); (2) histological subtype-tubular or having more than a $25 \%$ villous component; (3) grade of dysplasia-low or high (WHO guideline ${ }^{25}$ ).

The adenomas, 25 in total, which were removed from patients with a known mutation or belonging to a family with a known mutation were further analysed for MMR protein status by immunohistochemistry. Monoclonal mouse antibodies against $M L H 1$ (clone Gl68-728; Pharmingen, San Diego, USA) and MSH2 (Ab-2; Calbiochem, San Diego, USA) protein products were used. The paraffin sections $(3 \mu \mathrm{m})$ were fixed onto 3-aminopropyltriethoxysilane (APES; Sigma-Aldrich, Diesenhofen, Germany) coated slides, stretched for 30 minutes at $60^{\circ} \mathrm{C}$, and dried overnight at $37^{\circ} \mathrm{C}$. The sections were deparaffinised in xylene $(2 \times 10$ minutes $)$ and rinsed in $100 \%$ alcohol. The optimal antibody-antigen reaction was obtained by immersing the section in $200 \mu \mathrm{l}$ of blocking reagent $(2 \%$ block and $0.2 \%$ sodium dodecyl sulphate in maleic acid, pH 6.0; Boehringer Mannheim, Germany) and using a high pressure cooker for three sessions of five minutes at $115^{\circ} \mathrm{C}$, alternating with five minutes of incubation in a humid environment. After cooling for the third time, endogenous peroxidase activity was quenched by incubation with $30 \% \mathrm{H}_{2} \mathrm{O}_{2}$ in phosphate buffered saline (PBS) for $30 \mathrm{~min}$ utes. Following thorough washing in PBS, sections were immersed with the specific antibody in PBS with $1 \%$ bovine serum albumin (BSA) at a dilution of 1:500 for MLH1 and 1:100 for MSH2 antibody for one hour. Subsequently, the sections were washed three times with PBS and consecutively incubated for 30 minutes with rabbit antimouse peroxidase and goat antirabbit peroxidase diluted (1:50) in PBS-1\% BSA. The sections were submerged for 10 minutes in a solution of

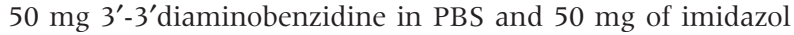
with $30 \% \mathrm{H}_{2} \mathrm{O}_{2}$, used as substrate for peroxidase. After rinsing with demi water, sections were counterstained with haematoxylin, washed with running water, and dehydrated with graded alcohol, dried, and covered with a slide.

\section{Statistical analyses}

Statistical comparisons between HNPCC and sporadic adenomas and within the two groups were made using the Mann-Whitney test when comparing a characteristic (size,
Table 1 Characteristics of hereditary non-polyposis colorectal cancer (HNPCC) and sporadic adenomas

\begin{tabular}{|c|c|c|c|c|c|}
\hline & \multicolumn{2}{|c|}{$\begin{array}{l}\text { HNPCC } \\
\text { adenomas }\end{array}$} & \multicolumn{2}{|c|}{$\begin{array}{l}\text { Sporadic } \\
\text { adenomas }\end{array}$} & \multirow[b]{2}{*}{$\mathrm{p}$ Value } \\
\hline & $\mathrm{n}$ & (\%) & $\mathrm{n}$ & $(\%)$ & \\
\hline \multicolumn{6}{|l|}{ Location } \\
\hline Proximal & 47 & $(50)$ & 39 & $(26)$ & \multirow{3}{*}{0.018} \\
\hline Distal & 29 & $(30)$ & 72 & (47) & \\
\hline Rectum & 19 & $(20)$ & 41 & $(27)$ & \\
\hline \multicolumn{6}{|l|}{ Size } \\
\hline$<5 \mathrm{~mm}$ & 70 & (70) & 67 & $(44)$ & \multirow[t]{2}{*}{$<0.001$} \\
\hline$\geqslant 5 \mathrm{~mm}$ & 30 & $(30)$ & 85 & (56) & \\
\hline \multicolumn{6}{|l|}{ Type } \\
\hline Tubular & 79 & (79) & 97 & (64) & \multirow[t]{2}{*}{0.010} \\
\hline Tubulovillous & 21 & $(21)$ & 55 & (36) & \\
\hline \multicolumn{6}{|l|}{ Dysplasia } \\
\hline Low grade & 68 & (68) & 114 & (76) & \multirow[t]{2}{*}{0.567} \\
\hline High grade & 32 & (32) & 38 & (25) & \\
\hline
\end{tabular}

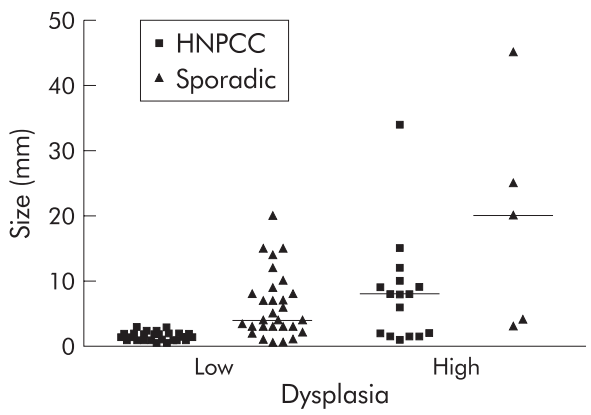

Figure 1 Distribution of proximal hereditary non-polyposis colorectal cancer (HNPCC) and sporadic adenomas by size and dysplasia (the horizontal lines indicate median size).

type, and dysplasia) with two variables and the corrected $\chi^{2}$ test was used for comparisons of a characteristic (location) with three variables. A p value of less than 0.05 was considered statistically significant.

\section{RESULTS}

Considering the two entire groups of adenomas (table 1), a significant difference was observed in location, size, and histology of HNPCC adenomas compared with sporadic adenomas $(\mathrm{p}=0.018, \mathrm{p}<0.001$, and $\mathrm{p}=0.010$, respectively). HNPCC adenomas had a proximal propensity $(50 \% v 26 \%$ of sporadic adenomas). The adenomas showed a wide range of sizes in both groups. The median size of HNPCC adenomas was $2.0 \mathrm{~mm}$ (range $0.5-34$ ) while sporadic adenomas had a median size of $5.5 \mathrm{~mm}$ (range 0.5-45). HNPCC adenomas were more often tubular in comparison with sporadic adenomas. Even though the HNPCC adenomas were more often small and tubular, they were similarly dysplastic as the larger and more often villous sporadic adenomas.

The proximal propensity was more evident in highly dysplastic HNPCC adenomas: high grade dysplastic HNPCC adenomas were more often (55\%) located proximal to the splenic flexure while only six (15\%) of the high grade sporadic polyps were right sided $(\mathrm{p}<0.001)$.

In the proximal colon, HNPCC adenomas were smaller in comparison with sporadic polyps $(\mathrm{p}=0.025)$ but they were more often highly dysplastic $(36 \% \vee 13 \%$; $<0.020)$ (fig 1$)$. When comparing size as well as dysplasia at one location (tables 2,3), the difference between the HNPCC and sporadic adenomas was clearly apparent. Larger HNPCC polyps ( $\geqslant 5$ $\mathrm{mm}$ ) in particular, in the proximal colon, were more often highly dysplastic $(\mathrm{p}<0.001)$ : in fact, all HNPCC adenomas $\geqslant 5$ 
Table 2 Dysplasia of hereditary non-polyposis colorectal cancer (HNPCC) adenomas by location and size

\begin{tabular}{lllllll}
\hline & \multicolumn{3}{c}{ Proximal $(\mathbf{n}=47)$} & \multicolumn{2}{c}{ Distal $(\mathbf{n}=29)$} & \multicolumn{2}{l}{ Rectum $(\mathbf{n = 1 9 )}$} \\
\hline Dysplasia & Low & High & Low & High & Low & High \\
& 30 & 17 & 25 & 4 & 9 & 10 \\
Size & & & & & & \\
$<5 \mathrm{~mm}$ & 30 & 6 & 17 & 2 & 8 & 3 \\
$\geqslant 5 \mathrm{~mm}$ & 0 & 11 & 8 & 2 & 2 & 6
\end{tabular}

Difference between $\geqslant 5 \mathrm{~mm}$ adenomas in the proximal and distal colon and between the proximal colon and rectum: $p=0.009$ and $p=0.07$, respectively.

\begin{tabular}{|c|c|c|c|c|c|c|}
\hline \multirow[b]{2}{*}{ Dysplasia } & \multicolumn{2}{|c|}{ Proximal $(n=39)$} & \multicolumn{2}{|c|}{ Distal $(n=72)$} & \multicolumn{2}{|c|}{ Rectum $(n=41)$} \\
\hline & $\begin{array}{l}\text { Low } \\
34\end{array}$ & $\begin{array}{l}\text { High } \\
5\end{array}$ & $\begin{array}{l}\text { Low } \\
45\end{array}$ & $\begin{array}{l}\text { High } \\
27\end{array}$ & $\begin{array}{l}\text { Low } \\
33\end{array}$ & $\begin{array}{l}\text { High } \\
8\end{array}$ \\
\hline \multicolumn{7}{|l|}{ Size } \\
\hline$<5 \mathrm{~mm}$ & 19 & 2 & 22 & 6 & 17 & 1 \\
\hline$\geqslant 5 \mathrm{~mm}$ & 15 & 3 & 23 & 21 & 16 & 7 \\
\hline
\end{tabular}

Difference between $\geqslant 5 \mathrm{~mm}$ adenomas in the proximal and distal colon and between the proximal colon and rectum were not significant.

mm were highly dysplastic. In the sporadic lesions this was not observed: only $25 \%$ of the large sporadic polyps at this site had high grade dysplasia.

In the rectum, large HNPCC adenomas were also more often highly dysplastic in comparison with sporadic adenomas $\geqslant 5$ $\mathrm{mm}$. However, this difference was only borderline significant $(\mathrm{p}=0.084)$. HNPCC adenomas in the distal colon were smaller than distal sporadic lesions $(66 \% \vee 39 \%<5 \mathrm{~mm} ; \mathrm{p}=0.047)$, mostly tubular ( $72 \% \vee 59 \%$; NS), and nearly always low grade dysplastic $(86 \% \vee 63 \% ; \mathrm{p}=0.020)$.

A significant difference was not only observed between the HNPCC and sporadic groups but also between the large HNPCC adenomas at the three locations. The large proximal HNPCC adenomas were more often highly dysplastic (100\% were highly dysplastic) than HNPCC adenomas in the distal colon $(22 \% ; p=0.001)$ whereas a borderline significant difference was detected between proximal and rectal adenomas (75\% highly dysplastic; $p=0.07$ ). The large HNPCC adenomas in the rectum were also significantly more often highly dysplastic in comparison with the HNPCC adenomas in the distal colon $(\mathrm{p}<0.03)$.

Eleven adenomas belonged to patients with a proven $M L H 1$ mutation while 11 adenomas were removed from patients with a proven $M S H 2$ mutation. Three adenomas were from two subjects who had not undergone genetic testing but a MLHI mutation had been detected in their families. In total, 15 adenomas, eight low grade and seven high grade dysplastic, showed loss of expression of either MLH1 or MSH2. The three adenomas from the two patients who had not undergone genetic testing all showed loss of MLHI staining, corresponding to the known mutation in their kindreds. Eight adenomas with loss of MLHl expression were located in the proximal colon and two were situated in the rectum. Loss of MSH2 expression was observed in three distal, one proximal, and one rectal polyp. The 10 adenomas, all from proven carriers, that had normal expression of MMR proteins were small and low grade dysplastic. Three of these adenomas were located in the proximal colon, four in the distal colon, and the remaining three were located in the rectum.

\section{DISCUSSION}

Our results differ from previous studies concerning morphological descriptions of adenomas in patients at risk of HNPCC. The results support the accelerated adenoma-carcinoma sequence of carcinogenesis in HNPCC but at the same time strongly suggest that lesions at different locations, proximal or distal in the colon or in the rectum, behave differently in this respect. More specifically, similar to the high frequency of hereditary non-polyposis colorectal carcinomas proximal to the splenic flexure, HNPCC adenomas have a right preponderance, although less so than carcinomas, and these right sided adenomas are more prone to malignant conversion compared with left sided adenomas.

The large group of HNPCC adenomas included in this study is representative of the Groningen HNPCC population as they comprise all the available benign neoplastic lesions consecutively removed over a 12 year period. The majority of HNPCC adenomas were obtained during surveillance examinations while sporadic adenomas were acquired during colonoscopy to diagnose clinical symptoms such as rectal blood loss, diarrhoea, and abdominal pain. The groups are thus not readily comparable and this probably explains why the HNPCC adenomas were smaller, more often tubular, and not more dysplastic than sporadic adenomas, findings in contrast with reports in the literature. ${ }^{911202627}$ It is noticeable however that the small and tubular HNPCC adenomas were not less dysplastic than the larger and more often villous sporadic cases, as would be expected. ${ }^{27}$ To reduce the discrepancy arising from comparing adenomas obtained through surveillance and diagnostic colonoscopies, we also evaluated only the index HNPCC adenomas, those adenomas found during the first colonoscopy (data not shown). The characteristics of these index neoplastic lesions did not differ from those of all HNPCC adenomas reported in the present study. In accordance with Green's observation, they were mostly small and tubular. ${ }^{28}$ The same team of gastroenterologists performed all colonoscopies. The number of small $(<5 \mathrm{~mm})$ HNPCC and sporadic adenomas in all sections of the colon illustrates the thorough endoscopic search in both groups throughout the entire colon. Nevertheless, we cannot exclude the fact that greater care was taken in the examination of the colons of HNPCC subjects than of those of other patients.

The prevalence and grade of dysplasia of adenomas in the general population differ with regard to sex, age, and geographic region..$^{27}{ }^{29-35}$ Any bias was minimised by including the same male to female ratio of adenomas in both groups. A sufficient number of age matched subjects however was not available. The histological characteristics of our control group were similar to those of Griffioen et al in another Dutch clinical investigation. ${ }^{36}$ The results from the control group also correspond to findings of several other studies. ${ }^{37}{ }^{38}$ However, other reports, mainly autopsy and surveillance studies, favour a substantially higher frequency of low grade dysplastic sporadic polyps and a lower frequency of villous lesions. ${ }^{17} 273033$ The proportion of proximal adenomas varies in the literature between $11 \%$ and $40 \%$ (Griffioen et al 17\% ${ }^{36}$ ).

The essential role of the proximal colon in the pathogenesis of HNPCC is evident from numerous reports of the high incidence of right sided (interval) carcinomas in HNPCC patients. ${ }^{16-810121439-42}$ In accordance with this, we found that HNPCC adenomas were located more often in the proximal colon than sporadic ones. The proximal propensity suggests alteration in the initiation of neoplastic growth in HNPCC in comparison with the general population. A recent report on the presence of microsatellite instability in both hyperplastic and dysplastic aberrant crypt foci in the colons of HNPCC patients also suggests a possible role for MMR dysfunction in the initiation of neoplastic lesions in HNPCC. ${ }^{43}$ However, Leach and others proposed that the adenomas in HNPCC develop on a sporadic basis only to provide a substrate for defective DNA MMR genes. ${ }^{44}$ 
We therefore attempted to substantiate Leach's theory or the "initiation" proposal by performing immunohistochemistry for gene products of $M L H 1$ and $M S H 2$ on adenomas from subjects with a known mutation. In accordance with most reports, absence of immunohistochemical staining was seen in two thirds of HNPCC adenomas-that is, in $44 \%$ of low grade and in all high grade dysplastic adenomas. ${ }^{45-50}$ Thus our data strongly suggest that DNA repair deficiency is not responsible for the initiation of an adenoma but determines the subsequent progression of the lesion. Although MMR dysfunction is not the first event, it is surely a very early occurrence in the tumorigenesis of HNPCC lesions and it heralds development to high grade dysplasia.

Our results illustrate that the proposed accelerated adenoma-carcinoma sequence in HNPCC is probably site specific - that is, limited to the proximal colon. While the group of HNPCC adenomas as a whole did not exhibit features of increased susceptibility to malignant conversion in comparison with sporadic adenomas, a difference was observed within the group of adenomas proximal to the splenic flexure. The large $(\geqslant 5 \mathrm{~mm}$ ) HNPCC adenomas in the proximal bowel were highly dysplastic suggesting more advancement in the malignant transformation than sporadic polyps of a similar size at this location. This and the fact that nine of the 15 HNPCC adenomas that showed loss of protein expression were located in the proximal colon emphasise the predilection of the proximal colon for tumorigenesis in HNPCC. Characteristics of HNPCC adenomas at specific sites in the large bowel have had limited attention to date as authors have only reported results on HNPCC adenomas in general. In contrast, sporadic adenomas have been described with regard to location. The National Polyp Study observed an increased frequency of high grade dysplasia in adenomas located distal to the splenic flexure but attributed this mainly to increased size and a villous component rather than to location per se. ${ }^{27}$ Nusko et al reported that sporadic right sided adenomas have a lower risk of becoming malignant compared with sporadic left sided adenomas. ${ }^{51}$ The reason for the reverse situation in HNPCC is still unclear. ${ }^{25}$ 52-54

In conclusion, half of the HNPCC adenomas were located in the proximal colon but this does not fully explain the proximal propensity of cancers. Our data showed that progression to high grade dysplasia was more common in proximal than in distal HNPCC adenomas, indicating a faster transformation rate from early adenoma to cancer in the proximal colon. MMR gene malfunction probably does not initiate adenoma development but is present at a very early stage of tumorigenesis and seems to herald the development of high grade dysplasia. At this time there is no explanation for this site specific behaviour of HNPCC lesions or for the susceptibility of epithelial cells in the proximal colon to somatic MMR gene mutations.

\section{ACKNOWLEDGEMENT}

This study was supported by the Dutch Cancer Society, grant RUG 98-1660.

\section{Authors' affiliations}

F E M Rijcken, J H Kleibeuker, Department of Gastroenterology, University Hospital Groningen, the Netherlands

H Hollema, Department of Pathology, University Hospital Groningen, the Netherlands

\section{REFERENCES}

1 Jarvinen HJ, Aarnio M, Mustonen $\mathrm{H}$, et al. Controlled 15-year trial on screening for colorectal cancer in families with hereditary nonpolyposis colorectal cancer. Gastroenterology 2000;1 18:829-34

2 Fearon ER, Vogelstein B. A genetic model for colorectal tumorigenesis. Cell 1990;61:759-67.

3 Watne AL. Colon polyps. J Surg Oncol 1997;66:207-14.
4 Roncucci L, Stamp D, Medline A, et al. Identification and quantification of aberrant crypt foci and microadenomas in the human colon. Hum Pathol 1991;22:287-94.

5 Vasen HF, Mecklin JP, Khan PM, et al. The International Collaborative Group on Hereditary Non-Polyposis Colorectal Cancer (ICG-HNPCC). Dis Colon Rectum 1991:34:424-5.

6 Messerini L, Mori S, Zampi G. Pathologic features of hereditary non-polyposis colorectal cancer. Tumori 1996;82:114-16.

7 Lynch HT, Smyrk TC, Watson P, et al. Genetics, natural history, tumor spectrum, and pathology of hereditary nonpolyposis colorectal cancer: an updated review. Gastroenterology 1993;104:1535-49.

8 Lynch HT, Smyrk T. Hereditary nonpolyposis colorectal cancer (Lynch syndrome). An updated review. Cancer 1996;78:1 149-67.

9 Jass JR, Smyrk TC, Stewart SM, et al. Pathology of hereditary non-polyposis colorectal cancer. Anticancer Res 1994;14:1631-4.

10 Jass JR. Colorectal adenomas in surgical specimens from subjects with hereditary non-polyposis colorectal cancer. Histopathology 1995;27:263-7.

11 Jass JR, Stewart SM. Evolution of hereditary non-polyposis colorectal cancer. Gut 1992;33:783-6.

12 Lanspa SJ, Lynch HT, Smyrk TC, et al. Colorectal adenomas in the Lynch syndromes. Results of a colonoscopy screening program. Gastroenterology 1990;98:1117-22.

13 Jass JR, Pokos V, Arnold JL, et al. Colorectal neoplasms detected colonoscopically in at-risk members of colorectal cancer families stratified by the demonstration of DNA microsatellite instability. J Mol Med 1996:74:547-51.

14 Vasen HF, Taal BG, Nagengast FM, et al. Hereditary nonpolyposis colorectal cancer: results of long-term surveillance in 50 families. Eur $J$ Cancer 1995;31 A: 1145-8.

15 Lanspa SJ, Jenkins JX, Cavalieri RJ, et al. Surveillance in Lynch syndrome: how aggressive? Am J Gastroenterol 1994;89:1978-80.

16 Lynch HT, Smyrk T, Jass JR. Hereditary nonpolyposis colorectal cancer and colonic adenomas: aggressive adenomas? Semin Surg Oncol $1995 ; 11: 406-10$

17 Jass JR, Young PJ, Robinson EM. Predictors of presence, multiplicity, size and dysplasia of colorectal adenomas. A necropsy study in New Zealand. Gut 1992;33:1508-14.

18 Jarvinen HJ, Mecklin JP, Sistonen P. Screening reduces colorectal cancer rate in families with hereditary nonpolyposis colorectal cancer. Gastroenterology 1995;108:1405-11.

19 Muto T, Bussey HJ, Morson BC. The evolution of cancer of the colon and rectum. Cancer 1975;36:2251-70.

20 Ponz-de LM, Della CG, Benatti P, et al. Frequency and type of colorectal tumors in asymptomatic high-risk individuals in families with hereditary nonpolyposis colorectal cancer. Cancer Epidemiol Biomarkers Prev 1998;7:639-41.

21 Hodgson SV, Bishop DT, Dunlop MG, et al. Suggested screening guidelines for familial colorectal cancer. J Med Screen 1995;2:45-51.

22 Vasen HF, Mecklin JP, Watson P, et al. Surveillance in hereditary nonpolyposis colorectal cancer: an international cooperative study of 165 families. The International Collaborative Group on HNPCC. Dis Colon Rectum 1993;36:1-4.

23 Vasen HF, van-Ballegooijen M, Buskens E, et al. A cost-effectiveness analysis of colorectal screening of hereditary nonpolyposis colorectal carcinoma gene carriers. Cancer 1998;82:1632-7.

24 Schoen RE, Corle D, Cranston L, et al. Is colonoscopy needed for the nonadvanced adenoma found on sigmoidoscopy? The Polyp Prevention Trial. Gastroenterology 1998;115:533-41.

25 Hamilton SR. The adenoma-adenocarcinoma sequence in the large bowel: variations on a theme. J Cell Biochem Suppl 1992;16G:41-6.

26 Mecklin JP, Sipponen P, Jarvinen HJ. Histopathology of colorectal carcinomas and adenomas in cancer family syndrome. Dis Colon Rectum 1986;29:849-53

27 O'Brien MJ, Winawer SJ, Zauber AG, et al. The National Polyp Study. Patient and polyp characteristics associated with high-grade dysplasia in colorectal adenomas. Gastroenterology 1990;98:371-9.

28 Green SE, Chapman PD, Burn J, et al. Clinical impact of colonoscopic screening in first-degree relatives of patients with hereditary non-polyposis colorectal cancer. BrJ Surg 1995:82:1338-40.

29 Eide TJ. The age-, sex-, and site-specific occurrence of adenomas and carcinomas of the large intestine within a defined population. Scand J Gastroenterol 1986;21:1083-8

30 Rickert RR, Auerbach O, Garfinkel L, et al. Adenomatous lesions of the large bowel: an autopsy survey. Cancer 1979;43:1847-57.

31 Johannsen LG, Momsen O, Jacobsen NO. Polyps of the large intestine in Aarhus, Denmark. An autopsy study. Scand J Gastroenterol 1989;24:799-806.

32 Bombi JA. Polyps of the colon in Barcelona, Spain. An autopsy study. Cancer 1988;61:1472-6.

33 Vatn $\mathbf{M H}$, Stalsberg $\mathrm{H}$. The prevalence of polyps of the large intestine in Oslo: an autopsy study. Cancer 1982;49:819-25.

34 Rubio CA, Saito Y, Watanabe M, et al. Non-polypoid colorectal neoplasias: a multicentric study. Anticancer Res 1999;19:2361-4

35 Gaglia P, Atkin WS, Whitelaw S, et al. Variables associated with the risk of colorectal adenomas in asymptomatic patients with a family history of colorectal cancer. Gut 1995;36:385-90.

36 Griffioen G, Bosman FT, Verspaget HW, et al. Colorectal adenomas: clinical and morphological aspects. A review of 166 polyps from 124 Dutch patients. Anticancer Res 1989;9:1685-9.

37 Johnson DA, Gurney MS, Volpe RJ, et al. A prospective study of the prevalence of colonic neoplasms in asymptomatic patients with an age-related risk. Am J Gastroenterol 1990;85:969-74. 
38 Cannon AL, Bishop DT, Samowitz W, et al. Colonic polyps in an unselected population: prevalence, characteristics, and associations. Am J Gastroenterol 1994;89:827-31.

39 Jass JR, Stewart SM, Stewart J, et al. Hereditary non-polyposis colorectal cancer-morphologies, genes and mutations. Mutat Res 1994:310:125-33.

40 Lynch HT, Watson P, Lanspa SJ, et al. Natural history of colorectal cancer in hereditary nonpolyposis colorectal cancer (Lynch syndromes I and II). Dis Colon Rectum 1988;31:439-44.

41 Mecklin JP, Jarvinen HJ. Clinical features of colorectal carcinoma in cancer family syndrome. Dis Colon Rectum 1986;29:160-4

42 Vasen HF, Hartog-Jager FC, Menko FH, et al. Screening for hereditary non-polyposis colorectal cancer: a study of 22 kindreds in The Netherlands. Am J Med 1989;86:278-81.

43 Pedroni M, Sala E, Scarselli A, et al. Microsatellite instability and mismatch-repair protein expression in hereditary and sporadic colorectal carcinogenesis. Cancer Res 2001;61:896-9.

44 Leach FS, Nicolaides NC, Papadopoulos N, et al. Mutations of a mutS homolog in hereditary nonpolyposis colorectal cancer. Cell 1993;75:1215-25

45 Thibodeau SN, French A, Roche PC, et al. Altered expression of hMSH2 and hMLH1 in tumors with microsatellite instability and genetic alterations in mismatch repair genes. Cancer Res 1996;56:4836-40.

46 Dietmaier W, Wallinger S, Bocker T, et al. Diagnostic microsatellite instability: definition and correlation with mismatch repair protein expression. Cancer Res 1997:57:4749-56.
47 Leach FS, Polyak K, Burrell $M$, et al. Expression of the human mismatch repair gene hMSH2 in normal and neoplastic tissues. Cancer Res 1996;56:235-40.

48 Cawkwell L, Li D, Lewis FA, et al. Microsatellite instability in colorectal cancer: improved assessment using fluorescent polymerase chain reaction. Gastroenterology 1995;109:465-71.

49 Chaves P, Cruz C, Lage P, et al. Immunohistochemical detection of mismatch repair gene proteins as a useful tool for the identification of colorectal carcinoma with the mutator phenotype. J Pathol 2000;191:355-60.

50 Marcus VA, Madlensky L, Gryfe R, et al. Immunohistochemistry for hMLH1 and hMSH2: a practical test for DNA mismatch repair-deficient tumors. Am J Surg Pathol 1999;23:1248-55.

51 Nusko G, Mansmann U, Altendorf HA, et al. Risk of invasive carcinoma in colorectal adenomas assessed by size and site. Int J Colorectal Dis 1997:12:267-71.

52 Bufill JA. Colorectal cancer: evidence for distinct genetic categories based on proximal or distal tumor location. Ann Intern Med 1990;113:779-88

53 Huang J, Papadopoulos N, McKinley AJ, et al. APC mutations in colorectal tumors with mismatch repair deficiency. Proc Natl Acad Sci USA 1996;93:9049-54

54 Philips SF, Pemberton J, Shorter RG. The large intestine: physiology, pathophysiology, and disease. Mayo Foundation. New York: Raven Press Ltd, 1991.

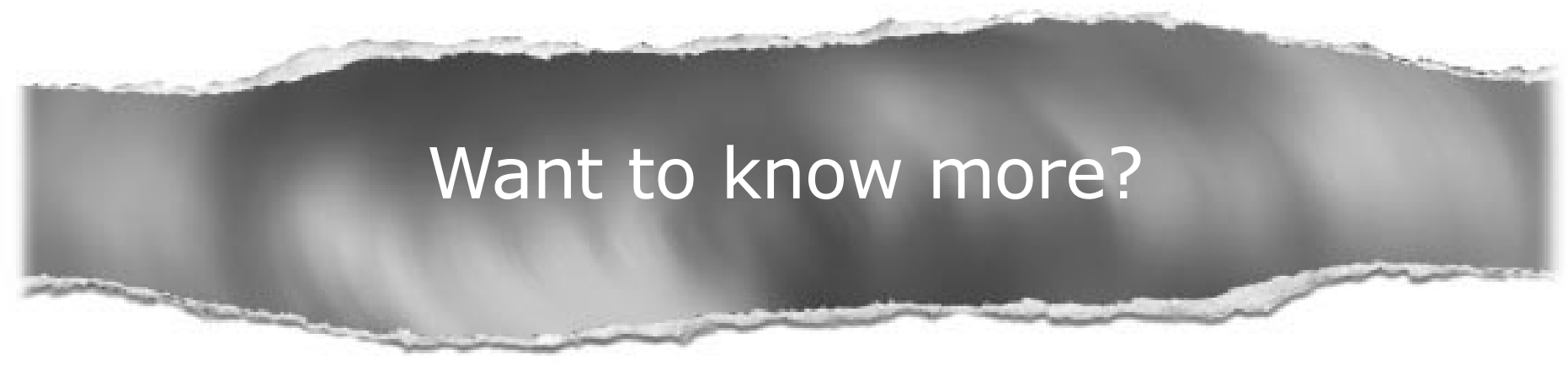

\section{Data supplements}

Limited space in printed journals means that interesting data and other material are often edited out of articles; however, limitless cyberspace means that we can include this information online.

Look out for additional tables, references, illustrations.

wwwv.gutjnl.com 